\title{
Effect of irrigation frequency and salinity levels of irrigation water on salt dynamics under drip irrigation in cabbage (L. Brassica Oleracea var. Capitata)
}

\author{
Parmod Sharma*, Sanjay Kumar and Narender ${ }^{1}$ \\ Department of Soil and Water Engineering, C.C.S. Haryana Agricultural University, Hisar (Haryana) India
}

\begin{abstract}
Use of poor quality water for agriculture production requires appropriate management strategies such as leaching of excessive salts, selection of salt tolerant crops, frequent application of water etc. Thus a field experiment was conducted at C.C.S. Haryana Agricultural University, Hisar to study the salt dynamics in soil under drip irrigation system on cabbage crop and to investigate the effect of frequency and salinity levels of irrigation water on cabbage. Two irrigation frequency: daily $\left(\mathrm{F}_{1}\right)$ and alternate day $\left(\mathrm{F}_{2}\right)$ irrigation and five salinity levels of irrigation water: canal water $\left(\mathrm{S}_{1}\right), \mathrm{EC}_{\mathrm{iw}} 3\left(\mathrm{~S}_{2}\right), 6\left(\mathrm{~S}_{3}\right), 9\left(\mathrm{~S}_{4}\right)$ and $12\left(\mathrm{~S}_{5}\right) \mathrm{dS} / \mathrm{m}$ treatments were considered in the experiment. With movement away from the plant (radial or vertically), salt concentration increased in the rootzone. More electrical conductivity was observed at the wetting front of the rootzone. In daily irrigation under saline water of $\mathrm{EC}_{\mathrm{iw}} 12 \mathrm{dS} / \mathrm{m}\left(\mathrm{F}_{1} \mathrm{~S}_{5}\right)$, the $\mathrm{EC}_{\mathrm{e}}$ values after 90 days of transplantation was increased by 206.4, 222.1, 244.4 and 264.1\% on comparing with initial values in 0-15, 15-30, 30-45 and 45-60 cm layers, respectively. In alternate day irrigation under saline water of $12 \mathrm{dS} / \mathrm{m}\left(\mathrm{F}_{2} \mathrm{~S}_{5}\right)$, the $\mathrm{EC}_{\mathrm{e}}$ values after 90 days of transplantation was increased by 279.2, 262.7, 270.1 and $280.2 \%$ on comparing with initial values in 0-15, 15-30, 30-45 and 45-60 cm layers, respectively.
\end{abstract}

Key Words : Cabbage, Drip irrigation, Saline water, Salt dynamics

View Point Article : Sharma, Parmod, Kumar, Sanjay and Narender (2018). Effect of irrigation frequency and salinity levels of irrigation water on salt dynamics under drip irrigation in cabbage (L. Brassica Oleracea var. Capitata). Internat. J. agric. Sci., 14 (2) : $413-418$, DOI:10.15740/HAS/IJAS/14.2/413-418. Copyright@ 2018: Hind Agri-Horticultural Society.

Article History : Received : 31.03.2018; Revised : 10.05.2018; Accepted : 24.05.2018

\footnotetext{
* Author for correspondence:

${ }^{1}$ Department of Farm Machinery and Power Engineering, C.C.S. Haryana Agricultural University, Hisar (Haryana) India
} 